\title{
Free-Form, High Energy Performance, Transparent Envelope
}

\author{
Luis A. Alonso ${ }^{1, a}$, Benito Lauret ${ }^{1, b}$ and Fernando Alonso ${ }^{2, c}$ \\ ${ }^{1}$ Building and Architectural Technology Department. School of Architecture. UPM. Avda. Ramiro de \\ Maeztu, s/n, 28040 Madrid, Spain \\ ${ }^{2}$ Languages and Systems and Software Engineering Department, School of Computing, UPM, \\ Campus de Montegancedo, s/n, 28660 Boadilla del Monte, Madrid, Spain \\ aluis@pyfarquitectura.com, benito.lauret@upm.es, ${ }^{\circ}$ falonso@fi.upm.es
}

Keywords: Monolithic silica gel insulation; aerogel; energy reduction; space saving; thermal insulation; transparent vacuum insulation panels; lightweight envelope; free-form panels; transparent panels; high energy efficiency.

\begin{abstract}
This article examines, from the energy viewpoint, a new lightweight, slim, high energy efficient, light-transmitting envelope system, providing for seamless, free-form designs for use in architectural projects. The research was based on envelope components already existing on the market, especially components implemented with granular silica gel insulation, as this is the most effective translucent thermal insulation there is today. The tests run on these materials revealed that there is not one that has all the features required of the new envelope model, although some do have properties that could be exploited to generate this envelope, namely, the vacuum chamber of vacuum insulated panels (VIP), the monolithic aerogel used as insulation in some prototypes, reinforced polyester barriers. By combining these three design components - the high-performance thermal insulation of the vacuum chamber combined with monolithic silica gel insulation, the free-form design potential provided by materials like reinforced polyester and epoxy resins -, we have been able to define and test a new, variable geometry, energy-saving envelope system.
\end{abstract}

\section{Introduction}

One of the major challenges for architects today is energy efficiency. This is a question that is gaining a lot of importance in the building field, where energy efficiency redounds not only to economic and environmental costs but also to user comfort and occupancy conditions.

Public administrations and professional associations the world over are trying to remedy the problem of energy inefficient buildings [1]. There are some international examples like the United States Department of Energy NIBS's Whole Building Design Guide 2010 [2], or the "Evaluation Standard for Green Building" [3] passed by the Chinese Ministry of Construction (MoC) (in 2006-08).

These policies indirectly promote an increase in the thicknesses of outer walls. On the other hand, there are other lines of research that aim to minimize the building skin thickness by optimizing its energy performance, also adding new architectural properties. These are alternatives that are now being studied and implemented by the Pritzker Architecture Prize winners Zaha Hadid, Frank Gehry, Rem Koolhaas, Herzog \& de Meuron, etc.

This research looks to those alternatives and to technology for new forms of generating energy efficiency and new materials developed from materials in use today. To determine the feasibility of the new envelope system that we propose, we have compiled, examined and run laboratory tests on the information and material provided by commercial brands. We have compared this information with data supplied by other independent scientific tests run by Moner-Girona, Roig, and Molins (CSIC) [4] and by independent laboratories like Zae Bayern (Germany) [5] or the University of Denmark [6].

After studying the results, this article sets out a novel envelope system based on a study of the families of lightweight commercial panels manufactured using an envelope assembly of translucent, silica gel-based thermal insulation materials, and determines its validity as a lightweight, slim, high energy efficient, light-transmitting envelope component. 


\section{Theoretical Study of the System}

Today's architectural vanguard demands a building system such as is proposed in this research. Existing similar systems are not absolutely free form and translucent, are not seamless and/or have a very limited thermal response. From the viewpoint of energy performance, we found that the insulation that best meets the needs of the new system that we propose is aerogel [7]:

a) Transparency: Monolithic aerogel light transparency can be as high as $87.6 \%$.

b) Insulation: on top of transparency, it is an excellent insulator [8], the thermal performance of a $70 \mathrm{~mm}$ nanogel-filled vacuum insulated panel (VIP) is better than a $270 \mathrm{~mm}$-thick hollow wall.

c) Lightness: aerogel is three times as heavy as air.

d) Versatility: monolithic aerogel can be shaped as required.

Commercial Systems. We have analyzed systems composed of granular and monolithic silica gel-filled polycarbonate, reinforced polyester and double-glazed VIPs.

a)Nanogel-filled cellular polycarbonate panels are the most widespread system on the market:

Strengths: This is a very lightweight material. It is a low-cost material. And, it is the least expensive envelope assembly. Weaknesses: Durability is low (10 years). These panels are very fragile to impact. The slimness of these panels means that they have acoustic shortcomings.

b)Only two types of reinforced polyester panels are commercialized despite potential of this material:

Strengths: Excellent mechanical properties. Durability is good (twice that of polycarbonate). Weaknesses: Existing systems have design faults, as they include internal aluminum carpentry.

c)Double-glazed VIPs are still at the prototype stage:

Strengths: Thanks to the combination of vacuum and aerogel insulation, they provide the slimmest and best insulation transparent $\left(0.5 \mathrm{~W} / \mathrm{m}^{2} \mathrm{~K}\right)$. Transparency levels are as high as $85 \%$. Weaknesses: This component is fragile. The high cost of molding glass into complex geometries rules out its use as a free form system. It is a system that depends on substructures and other components for use.

Findings: After a comparative analysis of over 147 commercial products, and the detailed evaluation of the best eight (Fig. 1), we can confirm that monolitic aerogel combined with a vacuum insulated chamber is the best insulation material. And the fiber reinforced polyester resin is the best protective envelope for the new system.

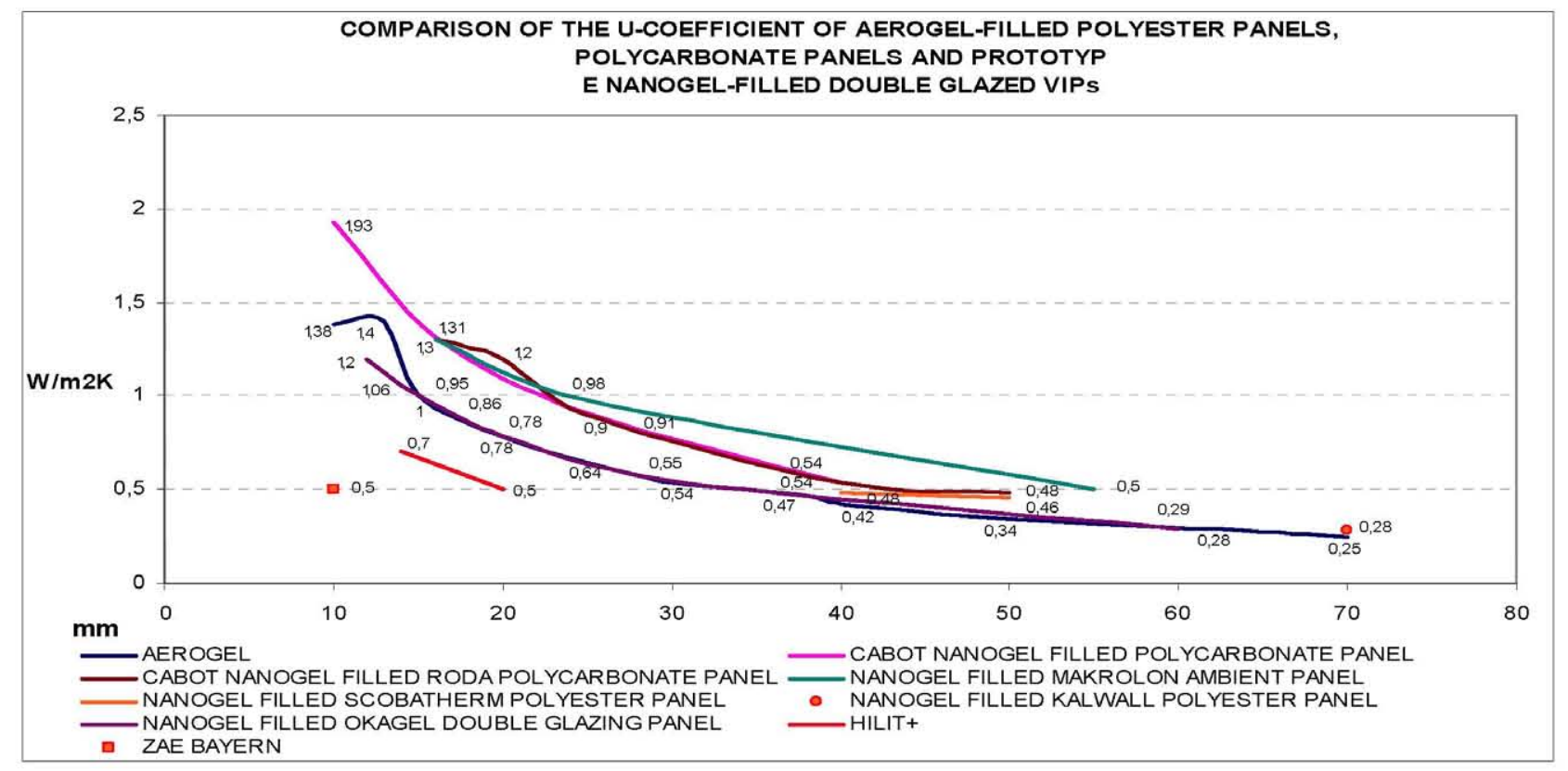

Fig. 1 Comparison of commercial systems and prototypes 


\section{Experimental Study}

Following up the results of the theoretical study, we now compare these findings with the results of an empirical experiment and computer-simulations of the real commercial panels.

Computer Simulation. We use the Design Builder program to conduct a trial by computer simulation under the same environmental conditions as the empirical trials run on the other panels Fig. 2 describes the behavior of a $25 \mathrm{~mm}$ aerogel sheet. We find that the test space has a uniform inside temperature of between 18 and $37^{\circ} \mathrm{C}$.

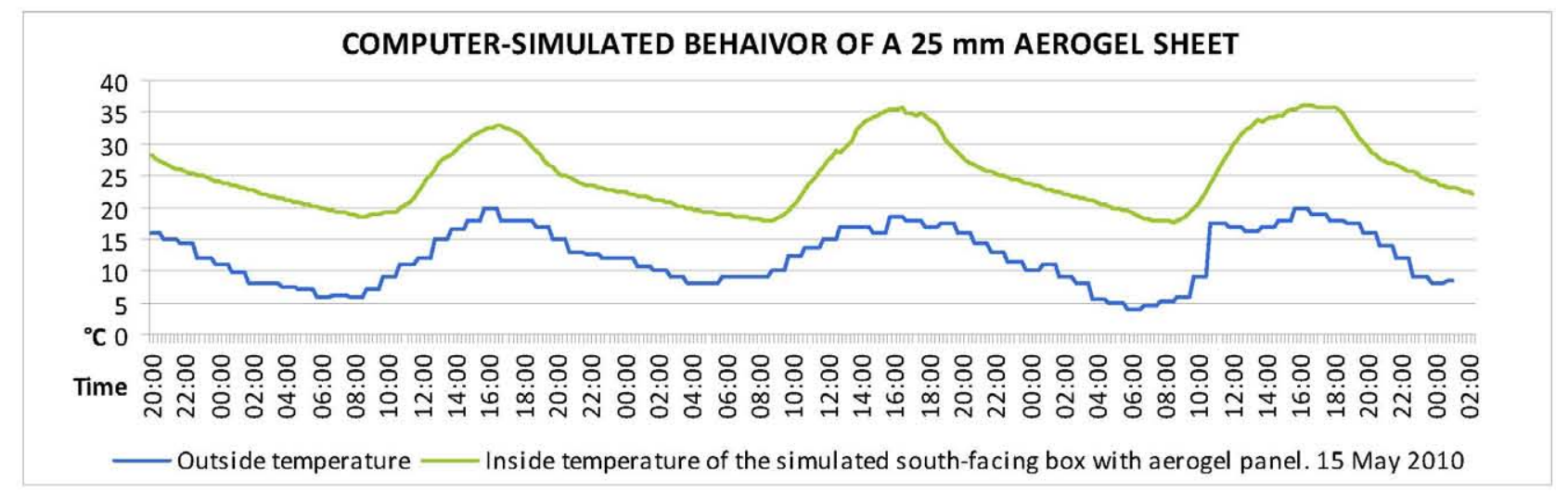

Fig. 2 Computer simulation

Empirical Trials. These trials were run at the Department of Building and Architectural Technology of the UPM's School of Architecture on boxes with an inner volume of $60 \times 60 \times 60 \mathrm{~cm}$, insulated with $20 \mathrm{~cm}$ of expanded polyurethane. One of the box faces is left open by way of a window. The study elements are placed in this opening using a specially insulated frame. The trial involves exposing two such boxes to a real outside environment to study their behavior. The two boxes have two different windows: one is fitted with $6+8+6$ double glazing with known properties as a contrast element and the other is fitted with the panel that we want to study. Data loggers are placed inside each box for monitoring purposes to measure and compare their inside temperature. The boxes are also fitted with a thermal sensor on the outside to capture the temperature to which they are exposed. The boxes are set in a south-facing position as this is the sunniest exposure.

We ran 28 temperature-measuring trials using this system. These trials were evaluated and compared with the computer-simulated aerogel data and data from the theoretical study (see comparison in Fig. 3), and we arrived at the following conclusion:

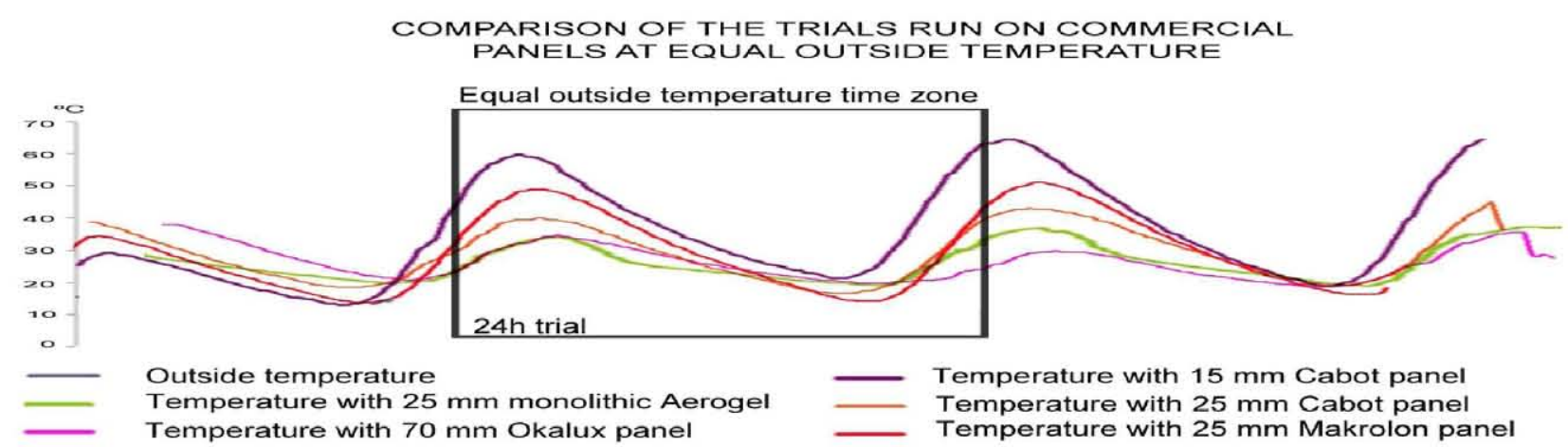

Fig. 3 Comparison of empirical data

The properties of the proposed component are better than double-glazed VIPs and reinforced polyester panels (Okalux and Kallwall) separately, as it combines the properties of the two to generate a new system and solve the problems specified earlier. 


\section{Free-Form, High Energy Performance, Transparent Envelope System $\left(\mathrm{F}^{2} \mathrm{TE}^{3}\right)$ Design}

We propose a free-form design envelope system fabricated with cellulose fibers and polyester resin (or acrylic-based organic resin), and a vacuum core insulated with monolithic aerogel at a pressure of $1 \mathrm{hPa}$. Being a self-supporting component, the system can perform structural functions, and seams between panels are concealed by an outer coating applied in situ.

Proposal for a Free-Form, Transparent, Energy Efficient Envelope System $\left(\mathbf{F}^{\mathbf{2}} \mathbf{T E}^{\mathbf{3}}\right)$. The $\mathrm{F}^{2} \mathrm{TE}^{3}$ is composed of the dry-seal connection of previously designed male and female-edged panels. Once the construction is in place, it is given an outer coating of fibers and resins and finally a gelcoat coating to protect the assembly from external agents.

Materials:

(a) A natural cellulose fiber-reinforced epoxy resin matrix, with an outer gelcoat coating to protect it from external agents; (b) a thermal/acoustical insulation component composed of a monolithic silica gel-filled vacuum chamber.

Dimensions:

The panel sizes will be $60 \times 60$ $\mathrm{cm}$ (length/width), and panel thickness will depend on whether the structure is self-supporting or a simple envelope. For modeling purposes, we have studied a $25 \mathrm{~mm}$-thick panel, composed of two sheets of 3 mm-thick reinforced resin and a vacuum core filled with monolithic silica gel (Fig.4).

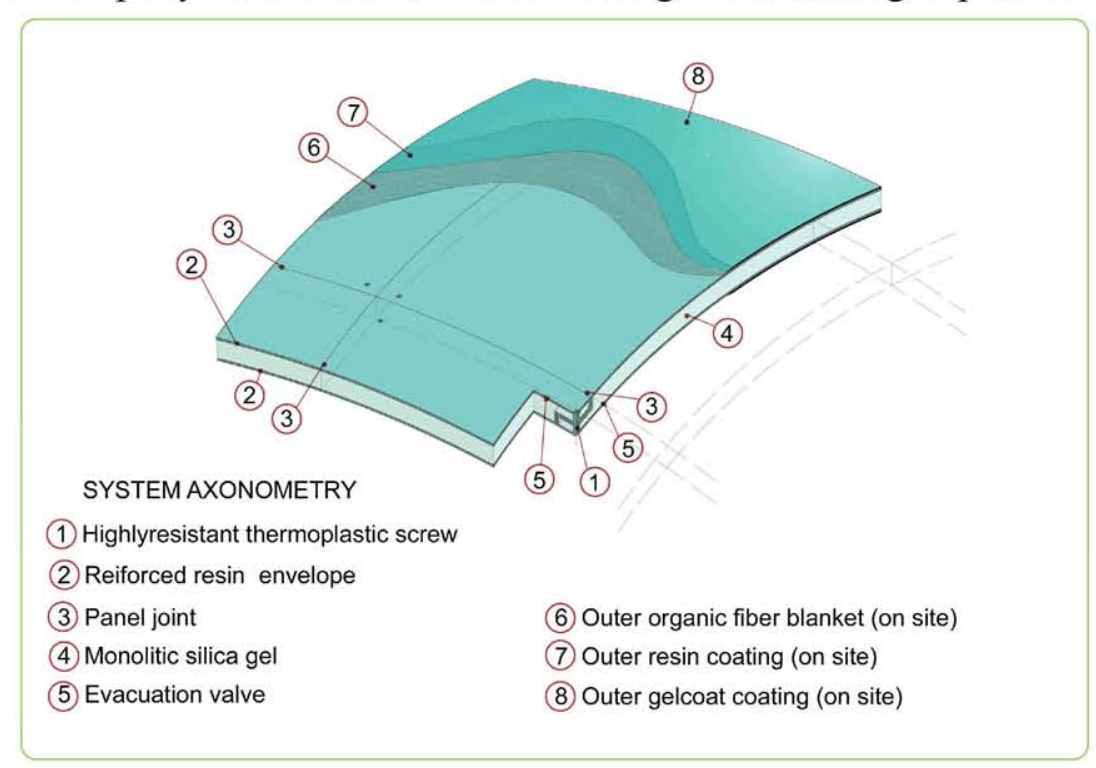

Fig. $4 \mathrm{~F}^{2} \mathrm{TE}^{3}$ system axonometry

The weight will be from 15 to $7 \mathrm{~kg} / \mathrm{m} 2$. Although dimensions could vary, the sheet width will be no greater than $600 \times 600 \mathrm{~mm}$, and the minimum admissible flexion radius will be approx. $4000 \mathrm{~mm}$. Specifications:

- Light transmittance, $\tau$ D65: from $59 \%$ to $85 \%$ approx.

- UV absorption: approx. $20 \%$

- Total energy: approx. $61 \%$

- Horizontal and vertical U value: $0.50 \mathrm{~W} / \mathrm{m} 2 \mathrm{~K}$

- Thermal conductivity coefficient: $\alpha 0.065 \mathrm{~mm} / \mathrm{m}{ }^{\circ} \mathrm{C}$, estimated

- Possible heat- and humidity-induced dilation: $3 \mathrm{~mm} / \mathrm{m}$ approx.

- Maximum temperature: should withstand temperatures of from $120^{\circ} \mathrm{C}$ to $250^{\circ} \mathrm{C}$ thanks to the outer glass fiber sandwich

- Weighted sound reduction value: estimated at 26-45 dB

Testing. The $\mathrm{F}^{2} \mathrm{TE}^{3}$ system with a thickness of $25 \mathrm{~mm}$ has been computer simulated to examine its energy-saving behavior compared with a computer-simulated monolithic aerogel of the same sides.

As shown in Fig. 5, although the plots are displaced, the $\mathrm{F}^{2} \mathrm{TE}^{3}$ system returns a result very close to what would be achieved with monolithic aerogel without a barrier envelope. Even with a barrier envelope, the $\mathrm{F}^{2} \mathrm{TE}^{3}$ performance almost equals aerogel in terms of heat loss, with a very similar flat curve, where the $U$ value is very small. 


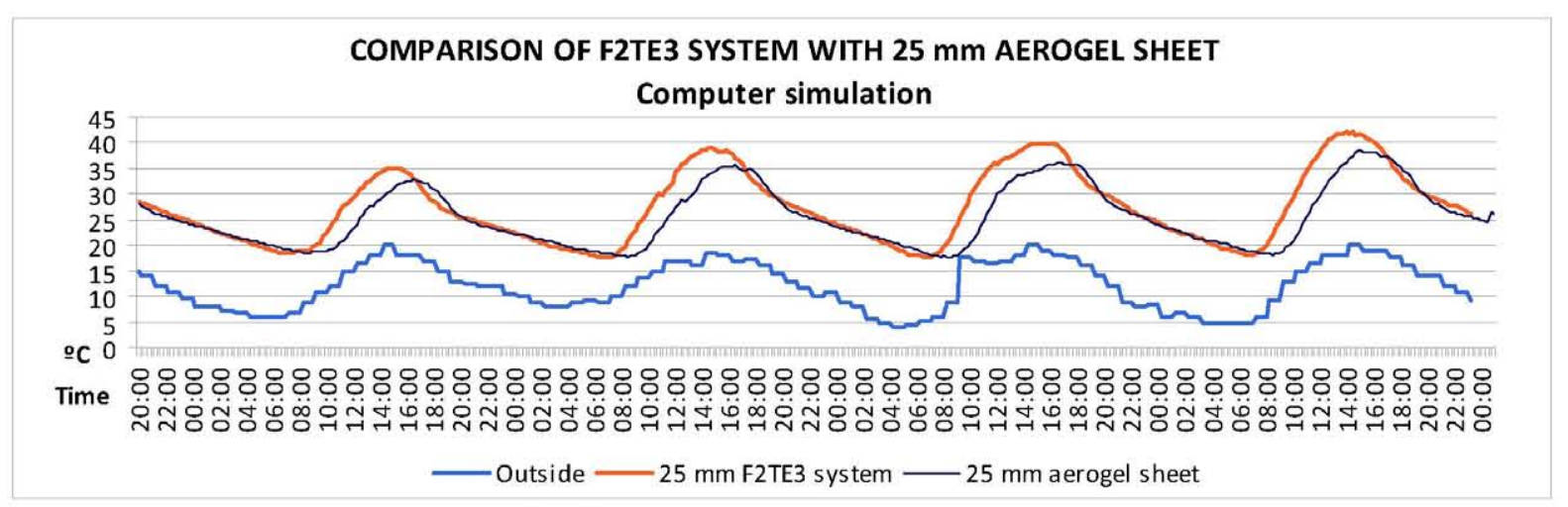

Fig. $5 \mathrm{~F}^{2} \mathrm{TE}^{3}$ compared with monolithic aerogel

\section{Conclusions}

The $\mathrm{F}^{2} \mathrm{TE}^{3}$ is a slim façade system that provides high energy efficiency, with a seamless surface, providing for variable geometry and the option of building self-supporting structures into the same transparent system skin.

Computer-simulated trials have shown it to have almost identical energy efficiency properties to monolithic aerogel systems and VIP envelopes. This system revolutionizes VIP systems, as it generates a transparent envelope but eliminates breakages due to fragility by substituting glass for a reinforced composite material. Additionally, it offers the option of generating variable geometry designs. The $\mathrm{F}^{2} \mathrm{TE}^{3}$ outperforms the systems existing on the market by combining some of the best properties of these systems and solving their weaknesses.

\section{References}

[1] Clinton Foundation: CCIs Energy Efficiency Building Retrofit Program, American College \& University Presidents' Climate Commitment, EPC Toolkit for Higher Education (2009).

[2] U.S. Building Commissioning and the WBDG Project Management Committee: Hole Building Design Guide. National Institute of Building Sciences (2010).

[3] Ministry of Construction of China (MoC): MOHURD's Three Star green building rating system. Ministry of Construction Green Building Evaluation Standard (2006-2008).

[4] L. Martín, J. Oriol Ossó, S. Ricart, A. Roig, O. García and R. Sastre: Organo-modified silica Aerogels and implications for material hydrophobicity and mechanical properties, Journal of Materials Chemistry, Vol.18 (2008), pp. 207-213 .

[5] U. Heinemann, H. Weinläder and H.-P. Ebert: Energy-efficient building envelopes: New materials and components. (ZAE BAYERN, Energy Working Group (EPA)) German Research Centre in terms of energy applications, Hamburg (2009).

[6] K. I. Jensen, F. H. Kristiansen and J. M. Schultz: HILIT+. Highly Insulating and Light Transmitting Aerogel Glazing for Super Insulating Windows, Department of civil engineering (BYG•DTU), Lyngby, Denmark (2005).

[7] I.L. Wong, P.C. Eames and R.S. Perera: A review of transparent insulation systems and the evaluation of payback period for building applications, Solar Energy, Vol. 81, No. 9 (2007), pp. 1058-1071.

[8] R. Baetensa, B. Petter Jellea, J. Vincent Thueb, M. J. Tenpierikd, S. Grynninga, S. Uvsløkka and A. Gustavsene: Vacuum insulation panels for building applications: A review and beyond, Energy and Buildings, Vol. 42, No. 2 (2010), pp. 147-172. 